\title{
The Influence of Work - family Conflict on Young Employees' Turnover Intention: The Role of Self-efficacy
}

\author{
Huimin Qi \\ Management College, Wuhan University of Technology, Wuhan, 430070, China \\ qhm0923@qq.com
}

Keywords: Influence of Work, Self-efficacy, Family conflict.

\begin{abstract}
Young workers are more likely to have higher levels of work-family conflict than their average counterparts, so the research on their work-family conflicts is even more important. This paper aims to explore the impact of work-family conflict on the turnover tendency of young employees and the moderating role of self-efficacy in them. Based on the analysis, the author puts forward the corresponding risk early warning system of young employees' turnover, providing inspiration for employees' turnover early warning area.
\end{abstract}

\section{Introduction}

The number and quality of young employees determine the development and the future of enterprises.Many successful companies take various measures to accelerate the training of young employees, while increasing the attractiveness of young employees of enterprises, reduce the turnover rate of young employees. However, young employees are in a special stage.From the stage of career development of young employees, the positioning of career development is not yet stable, career development is in the exploratory period, they need for more energy and time to work. From the stage of life ,young employees are also at a critical stage of family life.Newly married, raised children, especially the need to support and accompany their parents for the new generation of only child in China,young employees also bear more important family responsibilities. Under the dual pressures of two roles, young employees' work - family conflict as an important factor affecting employee turnover began to be studied.

Self-efficacy reflects the confidence of whether or not they have the ability to successfully complete a job in a different task scenario, which is relatively stable as a personality trait and determines the employee's attitude and behavior.It is important to understand the personality traits and tendencies of employees, to anticipate the tendency of young employees to leave their jobs and to take interventions to reduce risk.

Based on the literature search and review, it is found that although there are a lot of studies in recent years, we have explored the causes and consequences of work-family conflict from various perspectives, but the self-efficacy as a moderating factor to study work-family conflict is lacking. Therefore, this paper takes the young employees as the research object, takes the self-efficacy as the moderating variable, carries on the empirical test to the relationship between the work-family conflict and the employee's turnover tendency, and constructs the employee turnover early warning model based on the work family conflict. The study aims to enrich the field of influencing factors in the field of personnel turnover, to provide a reference for the staff turnover risk, and to further enhance the value of work-family conflict theory in human resources development and management.

\section{Theory and Research Hypothesis}

\subsection{The Impact of Work-family Conflicts on Employee Turnover Tendencies.}

Work-family conflict is a form of conflict of internal roles resulting from the incompatibility between the pressure from one role and the pressure from another, which is derived from the time distribution, emotional transmission, Spatial division, behavior patterns and gender roles are expected to be incompatible. According to Carlson, work-family conflict is generally divided into three forms: (1) time-based conflict (2) pressure-based conflict (3) behavior-based conflict. Time conflicts arise 
from competing roles for a limited amount of time,stress conflicts occur when the tension generated by a role affects the performance of another character, and the behavioral conflict occurs in a particular behavior pattern of a character and another character when the behavior pattern is incompatible.

Turnover tendency refers to a psychological tendency that an individual employee wants to move away from an existing organization or job. Western research suggests that work-family conflict has a significant impact on workplace behavior such as job satisfaction, job burnout, organizational commitment, and turnover intention. Studies have investigated the impact of Work InterferencewithFamily (WIF) and Family Interference with Work(FIW) on employee turnover intentions. There are also studies found that time conflicts, stress conflicts and behavioral conflicts have different predictors of employee turnover intentions. Domestic scholar studies have found that work-family conflicts have a predictive effect on employee turnover. Some scholars have explored the impact of working family conflicts on family and work at the Chinese situation, and the results show that employees in the Chinese scenario have more experience to work-family conflicts, and conflict of behavior has more influence on employee turnover. Studies have also shown that working in the Chinese context - the bi-directional nature of the family conflict will have a negative impact on the variables of the employee's job area, including the turnover intention. In fact, when a work-family conflict has seriously affected the behavior of young employees in both regions, and even beyond the psychological limits of employees, they may reduce the conflict by changing the status quo, and may ease the current conflict through resignation. In view of the above discussion, we propose the following hypotheses:

Hypothesis 1: The work of young employees' work-family conflict is positively related to turnover intention;

Hypothesis 1a: The work of young employees' work-family time conflict is positively related to turnover intention;

Hypothesis $1 \mathrm{~b}$ : The work of young employees'work-family stress conflict is positively related to turnover intention;

Hypothesis 1c: The work of young employees' work-family behavior conflict is related to turnover intention.

\subsection{The Role of Self-efficacy Moderating}

Self-efficacy is the core of social learning theory and social cognitive theory, and has been extensively studied in psychology and organizational behavior. The general self-efficacy is a stable individual trait, reflecting the individual's confidence in the ability to fulfill the job in a different task scenario. When individuals perceive higher levels of self-efficacy, they are more confident in coping with complex relationships and relationships, and are more likely to deal with work and family conflicts with a positive mindset, thereby reducing the idea of mitigating conflicts through resignation.Myeong-gu and Remus emphasize that individuals have the ability to perceive selfefficacy. If the individual perceives the higher self-efficacy, the higher the confidence of the unknown problem and the conflict, the higher the probability of success, so the self-efficacy help the individual to actively deal with working family conflict rather than choose a negative departure. In view of the above analysis, we propose the following hypotheses, the theoretical hypotheses of the study model shown in Figure 1.

Hypothesis 2a: Self-efficacy plays a moderating role in the work of young employees'work-family conflicts and turnover tendencies. When young employees have lower self-efficacy, the positive relationship between work-family conflict and turnover tendencies is stronger. When young employees have a high sense of self-efficacy, the negative relationship between work-family conflict and turnover tendencies is weak.

Hypothesis 2b: Self-efficacy plays a moderating role in the work of young employees'work-family conflict and turnover tendencies. When young employees have lower self-efficacy, the positive relationship between work-family conflict and turnover tendencies is stronger. When young employees have a high sense of self-efficacy, the negative relationship between work-family conflict and turnover tendencies is weak. 
Work-family conflict

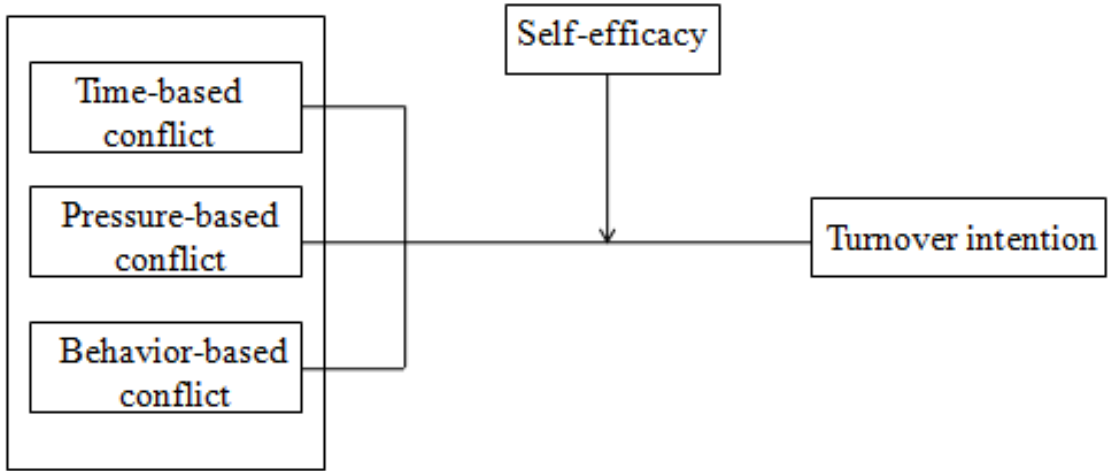

Figure 1. The theoretical hypothesis model of this study

\section{The Work - Family Conflict based Early Warning System}

\subsection{Build the Model}

Based on the analysis and model of the hypothesis, this paper establishes the early-warning model based on the conflict of the young employees' work-family conflict. Employees' work-family conflict and events in different ways manifested, and after a period of time up to a certain frequency and severity, exceeds the threshold and alarm.If the employees can't self-regulation at this time, companies can't adjust the staff's conflict and pressure, even leave it alone,employees may take negative emotions to deal with conflict or even turnover tendency. On the contrary, if employees can't adjust themselves at thistime, or enterprises fail to take measures to help employees to solve the psychological sense of pressure, Employees may take negative emotions to deal with conflicts, and even produce turnover tendencies.On the contrary, if employees can self-regulate the way, or enterprises to take mitigation measures to help employees to solve the psychological sense of pressure, employees will reduce the negative emotions to increase confidence in solving problems, reduce the work family conflict arising from the turnover tendency.Therefore, companies should pay attention to monitoring the work-family conflict of employees, design the threshold of work-family conflict, when the conflict reaches the threshold after the timely warning, reduce the turnover of employees tend to figure 2 .

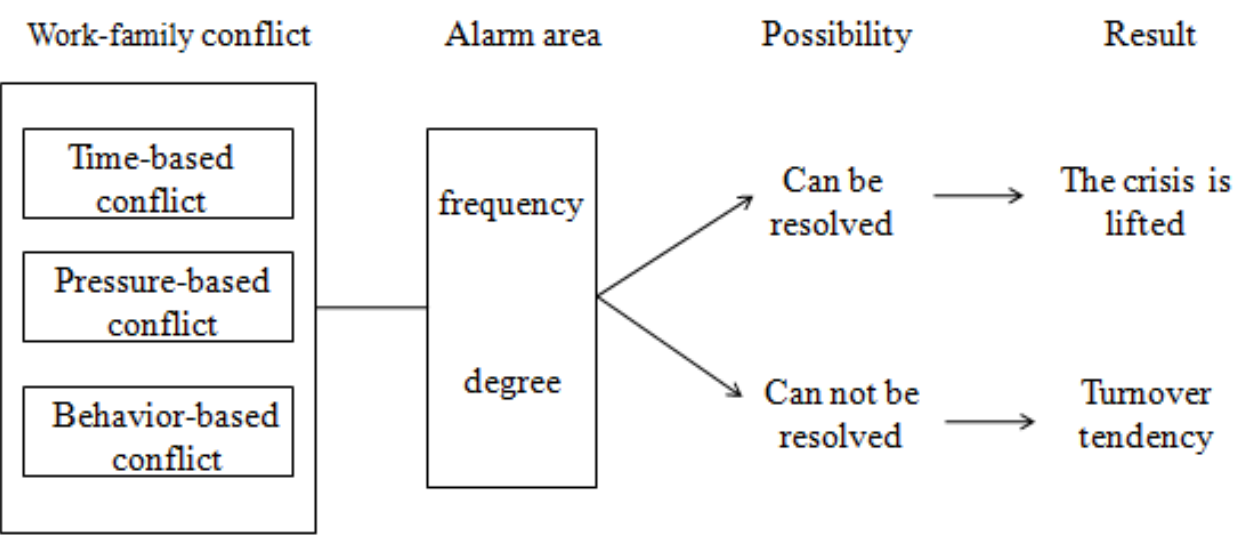

Figure 2. An Early Warning System of Turnover Intention Based on Working Family Conflict

The problem of work-family conflict can be found by observing employee observations and key events, and Table 1 illustrates the possible performance of different aspects of working families conflicts in the workplace.

\subsection{Pre - control Measures}

For employee work - family conflict problem, based on the study of this article, we can start to solve the following two aspects.

First, face the work of young employees'work-family conflict. Enterprises should be concerned about young employeeswork-family conflict, for the core employees, you can take a work-familyfriendly system design, including flexible working hours, certain family benefits,thereby enhancing 
the staff's sense of trust in the organization which can help it better solve the work-family conflict.In addition, for the heavy burden of young employees in the family,we can attract them through tempting salaries, so that they work hard at the expense of family time, which means saving employees by increasing their turnover costs.

Table.1 Examples of key events for work-family conflict performance

\begin{tabular}{|c|c|c|}
\hline LEVELINDICATORS & SECONDARYINDICATORS & POSSIBLE EVENTS \\
\hline \multirow{8}{*}{ Work-family conflict } & \multirow{3}{*}{ time-based conflict } & $\begin{array}{l}\text { Because of working hours to squeeze } \\
\text { family activities and complain }\end{array}$ \\
\hline & & $\begin{array}{l}\text { Because the family business delays the } \\
\text { time and cause the work to be affected }\end{array}$ \\
\hline & & $\begin{array}{l}\text { Because family affairs can't participate } \\
\text { in corporate group activities }\end{array}$ \\
\hline & \multirow{3}{*}{ pressure-based conflict } & Work in the workplace \\
\hline & & $\begin{array}{c}\text { As family business annoyance is } \\
\text { difficult to focus on work, efficiency is } \\
\text { reduced }\end{array}$ \\
\hline & & $\begin{array}{l}\text { Due to work stress and exhaustion lead } \\
\text { to family conflict complain }\end{array}$ \\
\hline & \multirow[b]{2}{*}{ behavior-based conflict } & $\begin{array}{l}\text { The use of solutions to family problems } \\
\text { has had a negative impact on job issues }\end{array}$ \\
\hline & & $\begin{array}{c}\text { Because of the use of work to solve the } \\
\text { problem of family problems have had a } \\
\text { negative impact and complain }\end{array}$ \\
\hline
\end{tabular}

Second, select high self-efficacy employees through the recruitment and selection. In the recruitment process to increase the test of young candidates self-efficacy of the content, and use selfefficacy as an indicator of employee who may have a work-family conflict problem. In addition, enterprises also need to guide employees to enhance self-efficacy. Through appreciation, encouragement and other means, managers can make the employees' self-efficacy in a variety of success and frustration experience to a certain degree of improvement, so as to enhance the confidence of employees to resolve work-family conflicts, and reduce the willingness of employees to solve problems through separation.

\section{Conclusion}

This paper studies the relationship between the work-family conflict of the young employees, the self-efficacy and the turnover intention.It aims to explore the relationship between the different dimensions of the work-family conflict and the risk of the young employees' turnover, and reveal the mechanism of the employee's self-efficacy. And the paper established a staff loss warning system based on work-family conflicts. Due to the limitation of time and conditions, it is necessary to carry out empirical analysis on the large-scale issuance of the questionnaire. The early warning model also needs the support of the empirical results. The risk threshold of the risk model should be further explored, and more research and analysis will be completed in the future.

\section{References}

[1] Amstad, F. T., Meier, L. L., Fasel, U., Elfering, A., \&Semmer, N. K...A meta-analysis of workfamily conflict and various outcomes with a special emphasis on cross-domain versus matchingdomain relations (Journal of Occupational Health Psychology,Washington DC, 2011 ) ,pp. 151169. 
[2] $\mathrm{Z}$ Xiang and $\mathrm{Z}$ Li.Investigation on the Factors of the Turnover of Young Employees in Chongqing Municipality (Youth Studies, Beijing, 2003), pp. 12-15+31.

[3] 3. Carlson, D. S., Kacmar, K. M. and Williams, L. J. Construction and Initial Validation of a Multidimensional Measure of Work - family Conflict (Journal of Vocational Behavior, NY, 2000), pp. $249-276$.

[4] Rosin, H. M., Korabik, K. Workplace variables, affective responses, and intention to leave among women managers (Journal of Occupational Psychology, Garlington, 1991), pp. 17 - 330.

[5] S Zhao. Analysis on the New Progress of Human Resource Management Theory and Its Future (Foreign Economics \& Management, Shanghai, 2011), pp. 1-10.

[6] Z Pan and Y Chen. The Relationship between Work Family Conflict and Turnover Intention in China (Enterprise Economy, Nanchang, 2012), pp.42-47.

[7] Z Chen, S Tian and J Wang. A Study on the Relationship between the Two - way and the Departure Tendency of Working Family Conflict. (Soft Science, Chengdu, 2014), pp.65-69.

[8] D Tang, Y Dong, G Yu, S Wen. Emotional Self - Efficacy: A New Research Theme (Advances in Psychological Science, Beijing, 2010), pp.598-604.

[9] G Shao, J Li, X Fan. Psychological Contract, Employee Satisfaction and Turnover Intention: An Analysis of Moderating Effects Based on Self - efficacy (Journal of Business Economics, Hangzhou, 2009), pp.29-35.

[10] Myeong-gu S, Remus I. The role of self-efficacy, goal, and affect in dynamic motivational selfregulation (Organizational Behavior and Human Decision Processes, 2009), pp.120-133.

[11]Rosin, H. M., Korabik, K. Workplace variables, affective responses, and intention to leave among women managers (Journal of Occupational Psychology, Garlington, 1991), pp.17 - 330.

[12] Y Luo, H Fan, J Zhang. Work-Family conflict Antecedents, Consequences and Intervention Strategies (Advances in Psychological Science, Beijing, 2007), pp.930-937.

[13]Z Gao, C Zhao. Why is it so difficult to work the family? Based on the Theory of work-family Boundaries (Advances in Psychological Science, Beijing, 2014), pp.552-568. 